\title{
MESTIZAJE Y COLONIZACIÓN EN LA ARGENTINA DE RUY DÍAZ DE GUZMÁN
}

\author{
Intermingling and colonization in Ruy Díaz de Guzmán’s La Argentina
}

\author{
Valentín Héctor Vergara* \\ Universidad de Buenos Aires \\ valentinhvergara@gmail.com
}

Palabras clave

literatura colonial;

mestizaje;

colonización;

Ruy Díaz de Guzmán

\begin{abstract}
Resumen
El objetivo del presente trabajo será analizar el estereotipo del mestizo como agente colonial descrito en La Argentina: Historia del descubrimiento y la conquista del Rio de la Plata (1612) de Ruy Díaz de Guzmán, escritor asunceño considerado como el primer autor mestizo del Río de la Plata. En primer lugar, se destacará brevemente la relación entre el proyecto colonizador de la Corona española y las intenciones de Díaz de Guzmán para vincular su linaje y a sí mismo con el porvenir del proyecto de los conquistadores. A continuación, se resaltará la importancia asignada en la obra a "los mancebos de la tierra" -criollos hispano-guaraníes de la zona de Asunción- para colaborar en la concreción de los objetivos de los españoles, y se evidenciarán las operaciones discursivas que Díaz de Guzmán lleva a cabo para referirse a aquellos en cuya sangre se mezclan colonizados y colonizadores.
\end{abstract}

\begin{abstract}
The aim of this paper is to analyse the idealization of the mestizo as a colonial agent in La Argentina: Historia del descubrimiento y la conquista del Río de la Plata (1612), written by Ruy Díaz de Guzmán, a XVIIth century author born in Asunción considered the first mestizo writer in the Río de la Plata. To begin with, we will take into consideration briefly the connection between the colonising project of the Spanish crown and Ruy Diaz's intentions to link his linage and himself to the future of the conquerors' project. Afterwards, we will discuss the importance assigned in the book to the "mancebos de la tierra" in meeting the Spanish goals, and analyse the intermingling as well as the discursive operations that Díaz de Guzmán uses to mention those whose lives' blood mixes that of the colonizers and the colonized.
\end{abstract}

\section{Keywords}

colonial literature;

intermingling;

colonization;

Ruy Díaz de Guzmán 


\section{Mestizaje y colonización en La Argentina de Ruy Díaz de Guzmán}

Las culturas de nuestro continente no pueden ser comprendidas si se ignora el peso del colonialismo en su devenir. Según Aníbal Quijano, la conquista de América significó el surgimiento de las primeras identidades de la modernidad. Basada en la codificación de diferencias biológicas, la idea de raza cristalizaba en principio las relaciones de poder mediante una jerarquía de supuesto orden natural entre conquistados y conquistadores. Quijano afirma que "la formación de relaciones sociales fundadas en dicha idea produjo en América identidades sociales históricamente nuevas: indios, negros y mestizos, y redefinió otras" (2014, p. 778). Esas nuevas identidades fueron afianzándose en la determinación de roles sociales asignados desde los agentes coloniales, por lo que "raza e identidad racial fueron establecidas como instrumentos de clasificación social básica de la población" (Quijano, 2014, p. 779). En este sentido, el surgimiento de la figura del mestizo implicó la necesidad de caracterizarlo. A nivel discursivo, representaba un significante vacío que, según el devenir históricopolítico de cada región, tomó distintas funciones y valoraciones. ${ }^{1} \mathrm{El}$ caso que analizaremos será el de Ruy Díaz de Guzmán, autor asunceño del siglo XVII. Considerado como el primer escritor mestizo del Río de la Plata, su obra principal, La Argentina: Historia del descubrimiento y la conquista del Río de la Plata ${ }^{2}$ (1612), aborda la historia de los primeros españoles en el Río de la Plata hasta la fundación de Santa Fe por Juan de Garay en $1573 .^{3}$ El relato de este autor ofrece una de las primeras concepciones de esta nueva identidad mestiza que surgía en el Paraguay, así como también refleja cuál era su valoración acerca de las distintas culturas que la atravesaban.

El contexto geopolítico en el que Ruy Díaz participó significó una experiencia inédita en América. La sociedad establecida en Asunción en el siglo XVII estaba conformada por indios guaraníes, un reducido conjunto de españoles y las primeras generaciones de mestizos de la región, conocidos como "mancebos de la tierra". Durante los siglos XVI y principios del XVII, este grupo de mestizos llevó a cabo, prácticamente sin ayuda externa, la expansión del dominio español sobre la zona del Paraguay. ${ }^{4}$ Bárbara Potthast señala que algunos "lograban ser aceptados como iguales por los españoles y hasta tuvieron acceso a puestos públicos" (Potthast, 1996, p. 41). Resultaría incompleto el análisis de la sociedad asunceña de entonces si se obviaran, por un lado, la violencia propia de cualquier proceso de colonización y, a su vez, las relaciones marcadas por la práctica del "cuñadazgo"

1. Como señala Francisco Raúl Carnese, "en la Península Ibérica, antes de la conquista americana, el término mestizo fue utilizado dentro del campo de la zoología y no para referir a la especie humana” (2019, p. 21). Según este autor, la procedencia del vocablo revela su carácter peyorativo.

2. Sobre el devenir del nombre de la obra de Ruy Díaz, ver Ricardo Rojas (1960). En el presente trabajo se tomará el título de la edición realizada por Silvia Tieffemberg (2012).

3. Este no habría sido el final del texto ideado por Ruy Díaz de Guzmán. En todas las copias y ediciones que se han encontrado hasta el presente, el texto culmina en el libro tercero; mientras que el autor hace referencia a que habría escrito un cuarto. No se conoce si efectivamente este último logró ver la luz alguna vez.

4. Como indica Pedro Ramón Caballero Cáceres, el caso de los mestizos en Paraguay, "a diferencia de otras regiones de Latinoamérica, era mejor, pues no eran marginados de la sociedad, sobre todo la primera generación de ellos, que conservaban el mismo status que sus padres españoles" (2019, p. 36). 
-costumbre corriente entre los aborígenes de la zona para entablar alianzas políticas- ${ }^{5}$ Debido a este contexto particular, la fisonomía mestiza de Asunción resultó una de sus características fundacionales. En este sentido, como señala Graciela Maturo, "los indios amigos constituyen la mediación indispensable para la creación de una estirpe paraguaya mestiza” (Maturo, 2011, p. 79). La centralidad que "los mancebos de la tierra" tuvieron en esta región para asentar la cultura y el dominio europeos fue sin duda determinante para la extensión del poderío español.

La crónica de Ruy Díaz de Guzmán nos acerca el primer testimonio desde la voz de un mestizo asunceño acerca de su propia identidad. En palabras de Efraím Cardozo, su obra "es la primera autorreflexión que surge de la mente de un nativo, en la recién constituida Provincia del Paraguay, acerca de sus orígenes" (Granda, 1979, p. 139). En sus escritos, el autor no revindica su identidad nativa, sino más bien delata cómo se percibía a sí mismo como la encarnación americana de su linaje español. Al respecto, Enrique de Gandía afirma que Ruy Díaz "era un mestizo asunceño con la mentalidad típica de un aristócrata peninsular" (Prieto, 2011, p. 20). Su filiación familiar, a pesar de su condición de "mancebo de la tierra", lo impulsaba como una figura importante dentro de la región, y el autor se encarga, a lo largo de su relato, de resaltar su destacado abolengo europeo. ${ }^{6}$ Ricardo Rojas asegura que Ruy Díaz cultivaba “con afán cortesano los prejuicios de la raza, de la casta y de la época: lealtad al Rey, amor a Dios, culto a la Iglesia, devoción a las jerarquías nobiliarias, fe aristócrata a las armas" (Rojas, 1960, p. 223). Las características señaladas por Gandía y Rojas resultan de la proyección que el autor efectúa de sí mismo en La Argentina, su obra principal. Según dice Ruy Díaz, esta lleva por objetivo rescatar del olvido la historia y las proezas de los primeros conquistadores españoles en la zona del Río de la Plata, empresa que tuvo a su abuelo materno y también a su tío abuelo paterno -Domingo Martínez de Irala y Alvar Núñez Cabeza de Vaca, respectivamente- como protagonistas. Omar Efraín Aliverti sostiene que "su condición de soldado y mestizo acrecienta la imagen de la autoridad sobre la «verdad», la que de algún modo percibe como su «heredad»" (2001, p. 120). Según este autor, la intención de la obra de Ruy Díaz es asentar en la memoria de sus contemporáneos "los méritos y fama de los fundadores de la "patria» que Guzmán asocia a la cadena de un linaje en relación al cual él mismo se exhibe como encarnación" (Aliverti, 2001, p. 120). Por lo tanto, escribir, para Ruy Díaz, es una forma de autolegitimar su identidad que, marcada por el mestizaje, requiere un anclaje en la fama de sus predecesores europeos para ser valorada. Loreley El Jaber apunta que la obra del cronista "es un derivado de la biografía de sus antepasados; y crea así lo que podría llamarse un aspecto autobiográfico derivativo de un sujeto o de un conjunto de sujetos que (...) ya poseen un lugar legalizado" (2006, p. 218). Esta estrategia discursiva utilizada para encumbrar sus raíces españolas esconde, por otro lado, el

\footnotetext{
5. Sobre la práctica del "cuñadazgo", Macarena Perusset afirma que "este tipo de relaciones amplias de parentesco respondía a la necesidad que estas comunidades tenían de crear vínculos de reciprocidad con otros grupos cercanos, con cuya alianza pudieran contar eventualmente. Así, toda mujer guaraní al ser para uno esposa y para otro hermana vinculaba a distintos grupos de descendencia mediante la relación de «cuñadazgo» que era otro de los aspectos primordiales de esta cultura" (2008, p. 253).

6. Ruy Díaz era nieto de dos de las figuras más destacadas de la zona del Río de la Plata en el siglo XVI: su abuelo materno, el gobernador Domingo Martínez de Irala -de cuya unión con la india Leonor nacerá Úrsula, madre de Ruy Díaz-, había logrado el apoyo de la soldadesca americana para consolidarse como líder de la región, para luego condenar al ostracismo a Alvar Núñez Cabeza de Vaca, tío abuelo de Ruy Díaz y adelantado oficial de la Corona, que había llegado para reemplazar al difunto Pedro de Mendoza.
} 
desconocimiento flagrante -al menos al interior del relato- de su herencia guaraní. Como indica Silvia Tieffemberg, su obra es la "legitimación de un abolengo al que se siente con derecho de pertenencia, y de borramiento de un origen estigmatizado y estigmatizador" (2012, p. 8).

La figura que se impone como protagonista en los hechos narrados en La Argentina es la de Domingo Martínez de Irala, adelantado de la región y abuelo del autor. ${ }^{7}$ En cambio, como indica Germán de Granda, "nada sabemos (...) del origen de la india Leonor, compañera del Gobernador Irala y abuela materna de Díaz de Guzmán” (Granda, 1979, p. 142). Al respecto, existe solo una referencia en la crónica sobre su procedencia mestiza. En la "Dedicatoria" que abre el texto, dirigida al Duque de Medina Sidonia, Ruy Díaz aclara que, "quedando mi padre en esta provincia, le fue forzoso asentar casa, tomando estado de matrimonio con doña Ursula de Irala, mi madre, hija del gobernador Domingo Martínez de Irala” (Díaz de Guzmán, 2012, p. 54). ${ }^{8}$ Como señala El Jaber, “el mestizaje no fue electivo y Ruy Díaz se encarga de remarcarlo porque es esta afirmación categórica la que delimita su lugar de enunciación y la que lo autoriza a ocuparlo" (1999, p. 1284). Por lo tanto, Ruy Díaz da a entender que su padre no eligió casarse con una mestiza, sino que lo hizo a la fuerza, como si remarcara que su herencia nativa fuera indeseable.

A nivel discursivo, la omisión de su herencia guaraní se evidencia a la hora de referirse a los aborígenes de la región. En este sentido, puede decirse que el criterio axiológico utilizado por Ruy Díaz para clasificar a los pueblos nativos se basa en la aceptación o el rechazo de las normas impuestas por los conquistadores, traducidas en categorías como indios "amigos" y "enemigos". No hay una mirada que juzgue la composición intrínseca de cada etnia señalada en la crónica, sino que la valoración de sus actividades se fijará según cuál sea su posición frente al invasor. Como señala Martín Prieto, "escribe como un europeo; y describe a los timbúes, a los guaraníes, a los caracaraes o a los querandíes con la misma extrañeza y estupefacción con que los describiría un español” (2011, p. 20).

El autor, en su obra, busca la integración del mestizo al proceso de colonización de la Corona española. No solo destaca a los protagonistas españoles, sino que también homogeniza las características de los "mancebos de la tierra" y niega cualquier herencia o influjo de la cultura guaraní sobre ellos. En el capítulo XVIII del primer libro de La Argentina, Ruy Díaz, luego de narrar cómo Martínez de Irala pudo "pacificar" la región de Asunción, y ser admirado tanto por españoles como indígenas debido a sus determinaciones sabias y justas, el cronista describe las características generales de los mestizos del Paraguay:

Son comúnmente de gran valor y ánimo, inclinados a la guerra y a las armas, las cuales manejan con mucho acierto y destreza, (...) son también buenos hombres de a caballo de ambas sillas y por

\footnotetext{
7. Como indica Maturo, "Ruy Díaz de Guzmán se muestra orgulloso de sus ancestros españoles, ilustres por vía paterna, pero no menos de su abuelo materno -también español, guipuzcoano- a quien convierte en el héroe de su relato" (Maturo, 2011, p. 76).

8. Tieffemberg indica que "el reconocimiento de los hijos es la mayor salvaguarda moral que acompaña el amancebamiento de los capitanes españoles con mujeres ofrecidas por el pueblo dominado" (Tieffemberg, 2012, p. 7).

9. Según Eduardo Subirats, "la estrategia y el concepto de pacificación presuponían la prerrogativa, por parte del conquistador, de imponer el sistema de un orden a la vez político y teológico. Prerrogativa absoluta que no admitía diálogo ni negociación (...): como si se trazara por primera vez una ley sobre un desierto" (Subirats, 1994, p. 75).
} 
su entretenimiento doman un potro, sobre todo muy obedientes a sus mayores y leales a $\mathrm{Su}$ Majestad. Las mujeres son de buen parecer, hábiles en la labor y costura, para muchos, nobles, de condición afable, discretas y sobre todo, virtuosas y honradas. (Díaz de Guzmán, 2012, p. 185)

Al describir a los mestizos de Asunción, Ruy Díaz se condecora a sí mismo con las características que les adjudica. No existen particularidades destacables de la cultura guaraní ni tampoco alguna insinuación de un posible mestizaje cultural. ${ }^{10}$ No hay una reivindicación de la identidad mestiza, sino un intento de asimilación de esta a las condiciones de dominio impulsadas por los europeos. Así, los "mancebos de la tierra", según el autor, solo representan las características propias del buen vasallo de la Corona, sin reconocer ninguna particularidad adicional fuera de esta visión arquetípica. Es evidente, entonces, que en la obra de Ruy Díaz existe el afán de borrar la buella de su origen indígena. Este término, desarrollado por Édouard Glissant, refiere a "toda una fracción de la realidad, arramblada de un pasado reacio que se repite una y otra vez en cada rincón de la vida” (2006, p. 22). Ruy Díaz, en verdad, en su intento por borrar sus orígenes - es decir, el peso de la huella de la identidad guaraní-, resalta, más bien, la existencia de ellos: su obra nace de la necesidad de autorizar ante la Corona su propio yo dentro de un sistema que, a priori, comprende a la otredad americana como perteneciente a un sustrato inferior. En este sentido, El Jaber afirma que "la figura del mestizo, cuya visión -por más imperialista que sea o aspire a ser- no llega a subsanar una falta clara en su lugar de pertenencia cultural" (2011, p. 76). Esa reivindicación de su ser, esa resistencia que busca sustentar su legitimidad dentro de un espacio político vivo, aunque utilice como estrategia discursiva el ocultamiento de su sangre aborigen, delata, más bien, su relación con su origen nativo en el devenir tortuoso de la conquista española. No existe, en las relaciones descritas por Ruy Díaz, la intención de un mestizaje cultural fomentado por el intercambio entre iguales, sino que la consecuencia para los "mancebos de la tierra”, en su búsqueda por ser aceptados dentro del sistema español, es la renuncia a su propia raíz guaraní.

En conclusión, luego de haber destacado las nuevas identidades surgidas a partir de la Conquista, se señaló la importancia del rol de los mestizos en la política de expansión y colonización española del Paraguay durante los siglos XVI y XVII. También se develaron las operaciones discursivas en la obra de Ruy Díaz de Guzmán para presentar su lugar como mestizo dentro de la sociedad asunceña. Esto puede verse en la reivindicación que realiza el autor sobre su abolengo hispánico y, a su vez, en el borramiento de cualquier distinción acerca de su identidad guaraní, como también en los reparos que exhibe en su escritura para referirse al casamiento forzoso de su padre con una mestiza. Al respecto, se explicitó la representación de los "mancebos de la tierra" en la obra de Ruy Díaz, en donde queda de manifiesto la homogeneización de sus características y la asimilación de estas a los valores sociales e individuales sostenidos por la cultura española, dejando de lado cualquier tipo de particularidad o influencia de su raíz guaraní. Por lo tanto, comprendimos que, siguiendo a Glissant, Ruy Díaz busca borrar la huella de su identidad nativa. Sin embargo,

10. Como señala Gruzinski, "la complejidad, lo imprevisto y la aleatoriedad parecen inherentes a las mezclas y los mestizajes" (2000, p. 61). Sin caer en posiciones monolíticas o maniqueas sobre el desafío que reviste hablar sobre mezclas de culturas, utilizamos el término "mestizaje cultural" para dar cuenta de un momento puntual en que resulten reconocibles elementos de las culturas indígenas y europeas preexistentes a la Conquista, sin analizar la heterogeneidad propia de cada una de ellas ni la dificultad que implica su estudio diacrónico, como tampoco las relaciones de poder mantenidas entre ellas. 
consideramos que este movimiento reivindicatorio del propio yo arrastra, justamente, la marca vacía de esa huella: la necesidad de validación por parte de un tipo de identidad dentro de una sociedad que la entiende como inferior. Ruy Díaz, en su afán por mimetizarse con los españoles de Asunción para fijar su inclusión en este sistema, al negar su herencia guaraní, finalmente, en ese acto, reconoce la posibilidad de vincularlo con sus ancestros nativos. Su intento de asimilación delata, entonces, su aceptación de los valores impuestos por los patrones coloniales de dominación y el consciente abandono de una parte de su ascendencia.

\section{Referencias bibliográficas}

Aliverti, O. E. (2001). Historia y ficción literaria en el siglo XVII: La Argentina de Ruy Díaz de Guzmán. En Strosetzki, C. (coord.), Actas del V Congreso Internacional de la Asociación Internacional Siglo de Oro (AISO) (pp. 117-122). Frankfurt, Vervuert.

Caballero Cáceres, P. R. (2019). El abordaje de la conquista del Río de la Plata en la obra de Ruy Díaz de Guzmán. En Regazzoni, S. y Cecere, F. (eds.), América: El relato de un continente (pp. 35-44). Venecia, Ca'Foscari.

Carnese, F. R. (2019). El mestizaje en la Argentina. Indigenas, europeos y africanos. Una mirada desde la antropología biológica. Buenos Aires, Editorial de la Facultad de Filosofía y Letras - Universidad de Buenos Aires.

Díaz de Guzmán, R. (2006). Tierra, sangre y nombre. La escritura de la identidad. Jitric, Noe. En Aventuras de la critica: escrituras latinoamericanas en el siglo XXI (pp. 215-222). Córdoba, Alción.

Díaz de Guzmán, R. (2011). Un país malsano. La conquista del espacio en las crónicas del Río del Río de la Plata (siglos XVIy XVII). Rosario, Beatriz Viterbo Editora / Universidad Nacional de Rosario.

Díaz de Guzmán, R. (2012). Argentina: historia del descubrimiento y conquista del Río de la Plata (S. Tieffemberg, ed.). Buenos Aires, Editorial de la Facultad de Filosofía y Letras - Universidad de Buenos Aires. (Original de 1612.)

El Jaber, L. (1999). Ruy Díaz de Guzmán: la vindicación de la conquista como estrategia discursiva. En Brizuela, M., El hispanismo al final del milenio (pp. 1281-1291). Córdoba, Asociación Argentina de Hispanistas.

El Jaber, L. (2006). Tierra, sangre y nombre. La escritura de la identidad. En Jitrik, N., Aventuras de la critica: escrituras latinoamericanas en el siglo XXI. Córdoba, Alción.

El Jaber, L. (2011). Un país malsano. La conquista del espacio en las crónicas del Río de la Plata (siglos XVI y XVII). Rosario, Beatriz Viterbo.

Glissant, E. (2006). Tratado del Todo-Mundo. Barcelona, El Cobre.

Granda Gutiérrez, G. de (1979). Personalidad histórica y perfil lingüístico de Ruy Díaz de Guzmán (¿1560? - 1629). Thesaurus: Boletín del instituto Caro y Cuervo, 34 (1-3), 138-163. 
Gruzinski, S. (2000). El pensamiento mestizo. Barcelona, Paidós.

Maturo, G. (2011). El bumanismo en la Argentina indiana y otros ensayos sobre la América colonial. Buenos Aires, Biblos.

Perusset, M. (2008). Guaraníes y españoles. Primeros momentos del encuentro en las tierras del antiguo Paraguay. Anuario del Centro de Estudios Históricos "Prof. Carlos S. A. Segreti". Córdoba, Centro de Estudios Históricos, 8. 8, 245-264.

Potthast, B. (1996). Paraíso de Mahoma o país de las mujeres. Asunción, Instituto Cultural ParaguayoAlemán.

Prieto, M. (2011). Breve historia de la literatura argentina. Buenos Aires, Taurus.

Quijano, A. (2014). Colonialidad del poder, eurocentrismo y América Latina. En Cuestiones y horizontes: de la dependencia bistórico-estructural a la colonialidad/descolonialidad del poder (pp. 777-832). Buenos Aires, CLACSO.

Rojas, R. (1960). Historia de la literatura argentina (tomo III). Buenos Aires, Kraft.

Subirats, E. (1994). El continente vacio. La conquista del Nuevo Mundo y la conciencia moderna. México DF, Siglo XXI.

Tieffemberg, S. (2012). Ruy Díaz de Guzmán, el cuerpo del territorio. En Díaz de Guzmán, R., Argentina: historia del descubrimiento y conquista del Río de la Plata (pp. 7-21). Buenos Aires, Editorial de la Facultad de Filosofía y Letras - Universidad de Buenos Aires.

* Valentín Héctor Vergara es Profesor en Letras por la Universidad de Buenos Aires (UBA). Ha dado clases de Lengua y Literatura en los niveles medio y superior, así como también fue coordinador de talleres literarios para adultos. Actualmente se encuentra realizando el Doctorado en Literatura en la Facultad de Filosofía y Letras de la Universidad de Buenos Aires, con el proyecto de investigación titulado "El tópico de la guerra en la obra de Ruy Díaz de Guzmán: modelos centrales, reconfiguraciones americanas", dirigido por la Dra. Silvia Tieffemberg. También es adscripto al Instituto de Literatura Hispanoamericana (FFyL-UBA), donde lleva adelante la investigación "Lecturas de textos rioplatenses coloniales en el siglo XIX", tutelado por la Dra. Inés de Mendonça.

RECIBIDO: $10 / 12 / 2020$

ACEPTADO: 30/08/2021 